\title{
Influence of the Deuteron Energy on the Testing Volume of IFMIF and Its Impact on Other Parameters*
}

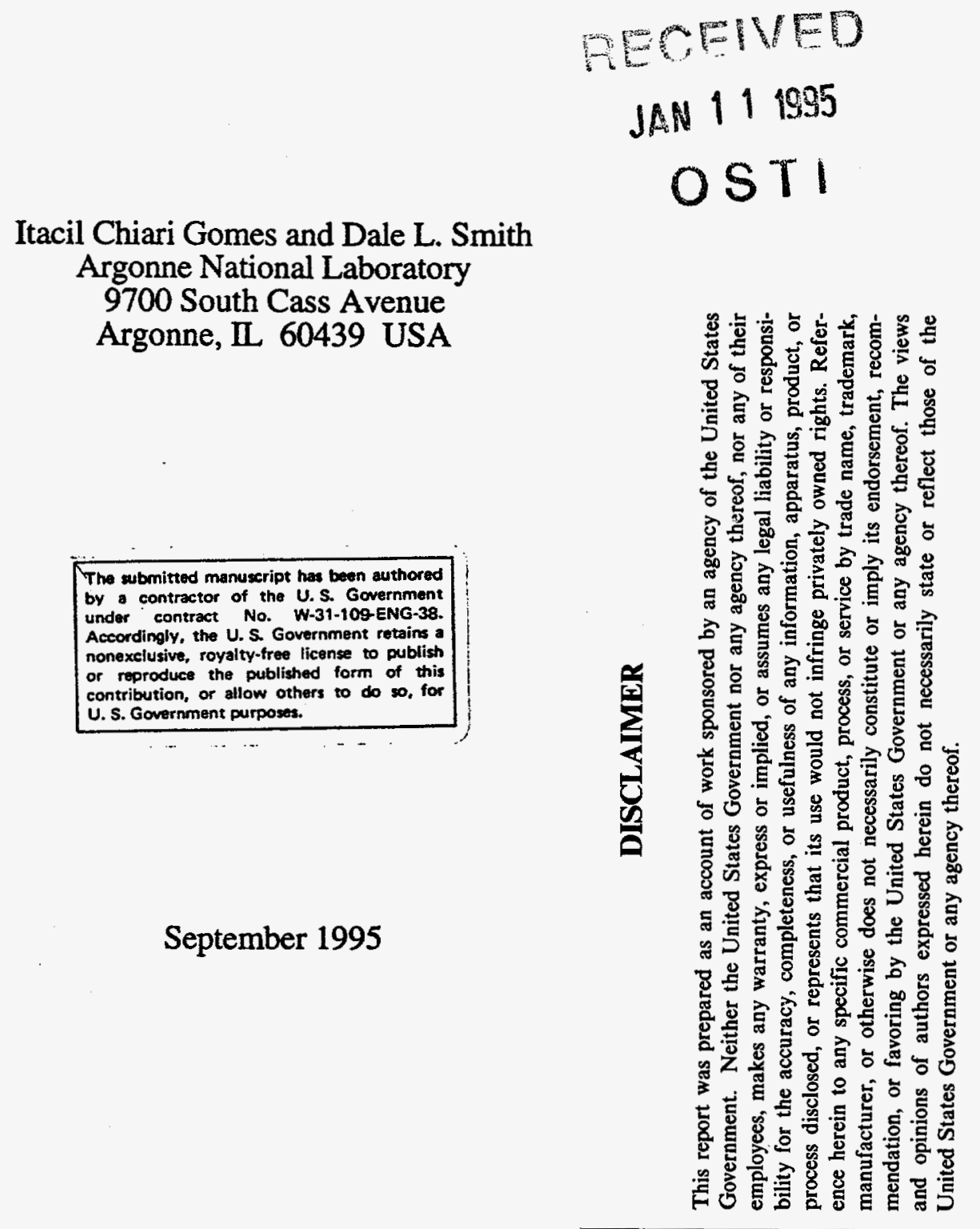

\footnotetext{
*Work supported by the U. S. Department of Energy, Office of Fusion Energy, under Contract No. W-31-109-Eng-38.

To be presented at the 16th IEEE/NPSS Symposium on Fusion Engineering, September 30 - October 5, 1995, Champaign, Illinois USA.
} 


\section{DISCLAMMER}

Portions of this document may be illegible in electronic image products. Images are produced from the best available original document. 


\title{
Influence of the Deuteron Energy on the Testing Volume of IFMIF and Its Impact on Other Parameters
}

\author{
Itacil Chiari Gomes and Dale L. Smith
}

Argonne National Laboratory

9700 S. Cass Ave, Bldg 207, Argonne, Il 60439

\begin{abstract}
The influence of the energy of the deuteron beam on irradiation parameters of IFMIF is analyzed. The main purpose of this paper is to identify possible positive and negative impacts on irradiation parameters that an increase in the deuteron energy of the IFMIF beam can cause. Several parameters of the facility, such as neutron generation rate, number of neutrons with energy above $20 \mathrm{MeV}$ at the source and in the test assembly, volume with dpa rate above a threshold value, gas production, and gradient of the atomic displacement rate, are analyzed and conclusions are drawn based on the calculated values. It is shown that an increase in the deuteron energy to $40 \mathrm{MeV}$ does not produce a significant negative impact for the elements analyzed, but instead is beneficial in producing nuclear responses more similar to a fusion environment than the lower deuteron energies.
\end{abstract}

\section{INTRODUCTION}

The conceptual design activity for the International Fusion Materials Irradiation Facility (IFMIF) is under way. The size of the testing volume is one of the most important parameters of the facility because it has several implications in the design of the test assembly region and on the positioning of the experimental apparatus. The volume of the testing region with damage rates above a specified value is a function mainly of two parameters, namely the beam current and the deuteron energy.

To increase the testing volume one can either increase the beam current or the deuteron energy. The first option has the disadvantage of increasing the overall cost of the facility almost linearly with the current. The second option has the advantage of being less costly but on the other hand one sees an increase in the neutron high energy tail. The second option is the main subject of this paper.

The implications, in terms of neutron production of a higher deuteron energy for the same beam current, are a higher neutron generation rate at the target region and a higher average neutron energy. Regarding nuclear responses, the generation of a larger fraction of the neutrons at the source with energies above $20 \mathrm{MeV}$ is considered by some as an important concern.

This paper presents an analysis of the impact on irradiation parameters, such gas production to dpa ratios, volume with dpa rate above a threshold value, and flux gradient, of the deuteron energy in the range of 30 to $40 \mathrm{MeV}$. It is shown that, contrary to what many believe, the increase of the deuteron energy from 35 to $40 \mathrm{MeV}$ produces a neutron environment that in many cases, mimics a fusion reactor better than the one produced by either 30 and $35 \mathrm{MeV}$ deuteron beams.

\section{Neutron Generation Analysis for Different Deuteron Energies}

The advantage of increasing the deuteron energy is to produce a higher neutron generation rate at the target region, and as a consequence, a larger volume with high damage rates for material testing. In this section, an analysis of the number of neutrons available at the source and inside the test assembly region is presented. Table 1 shows the total neutron generation from a deuteron beam of $250 \mathrm{~mA}$ for five different deuteron energies $(20,25,30,35$, and $40 \mathrm{MeV})$. The numbers represent total neutron generation rate independent of energy, angle, or spatial distribution of the neutrons. Table 1 also shows the average energy of the neutrons generated (for each incident deuteron energy), again independent of the angle and spatial position of the neutrons.

As one can notice, increasing the deuteron energy increases significantly the number of neutrons generated for the same beam current. Increasing the deuteron energy from 30 to 40 $\mathrm{MeV}$ represents an increase in the neutron generation by a factor of 1.62 , which is roughly equivalent to an increase in the current from 250 to $400 \mathrm{~mA}$. The difference from 35 to 40 $\mathrm{MeV}$ deuterons is about $25 \%$ in terms of neutron generation or roughly equivalent to the increase the beam current from 250

Table 1. Total neutron generation from a deuteron beam of $250 \mathrm{~mA}$ incident on a lithium target.

\begin{tabular}{|c|c|c|}
\hline $\begin{array}{c}\text { Deuteron } \\
\text { Energy }(\mathrm{MeV})\end{array}$ & $\begin{array}{c}\text { Total Neutron } \\
\text { Generation }(\mathrm{n} / \mathrm{sec})\end{array}$ & $\begin{array}{c}\text { Average Neutron } \\
\text { Energy }(\mathrm{MeV})\end{array}$ \\
\hline 20 & $3.12 \mathrm{e}+16$ & 4.55 \\
25 & $4.71 \mathrm{e}+16$ & 5.32 \\
30 & $6.53 \mathrm{e}+16$ & 6.09 \\
35 & $8.53 \mathrm{e}+16$ & 6.84 \\
40 & $1.06 \mathrm{e}+17$ & 7.54 \\
\hline
\end{tabular}


to $310 \mathrm{~mA}$. Clearly, one can say that there is a significant advantage in increasing the deuteron energy in terms of neutron generation alone.

The numbers shown in Table 1 are not the number of neutrons that actually reach the test assembly region, they represent the total production from the $\mathrm{D}-\mathrm{Li}$ reaction without any description of the angular and spatial distributions. It is well known that the higher the deuteron energy the more forward peaked is the angular distribution of the generated neutrons [1]. Based on this, it is reasonable to say that, if one increases the deuteron energy, a larger number of high energy neutrons will be present inside the test assembly region.

To define the magnitude of the such an impact on the neutron energy spectrum, a neutron transport analysis, with the MCNP code [2], was performed. The material loading in the test assembly region was represented by Iron $50 \%$ dense. The beam footprint on the jet was assumed to be $5 \mathrm{~cm}$ high and 20 $\mathrm{cm}$ wide. Table 2 shows the calculated results for the number of neutrons (neutron current) crossing areas of $1 \mathrm{~cm} \times 2 \mathrm{~cm}$, perpendicular to the direction of the beam, which have their center coincident with the center line of the beam. The position of these areas, in the direction of the beam, are: a) zero $\mathrm{cm}$ from the back-plate, b) $5 \mathrm{~cm}$ from the back-plate, and c) $10 \mathrm{~cm}$ from the back-plate. The integral neutron current for these areas are presented for discrete neutron energy ranges and for the total over all energies.

From Table 2 it can be observed that for $40 \mathrm{MeV}$ deuterons, neutrons with energy above $20 \mathrm{MeV}$ account for roughly $8 \%$ to $10 \%$ of the total number of neutrons, for $35 \mathrm{MeV}$ deuterons that number ranges from $5.5 \%$ to $7 \%$ of the total and for 30 $\mathrm{MeV}$ deuterons it is from $3.8 \%$ to $4.3 \%$. It is important to notice that most of these neutrons are in the range from 20 to $30 \mathrm{MeV}$ (about $60 \%$ for all cases). Then, one can say that, going to a higher deuteron energy does not produce a dramatic increase in the number of neutrons above $20 \mathrm{MeV}$ inside the test assembly region that can completely wash out the advantages gained in terms of higher neutron yield.

\section{Gas Generation for Selected Elements.}

There are several neutron reactions that lead to gas production. Most of those reactions require a minimum neutron energy to be triggered (threshold type reaction) and the reaction rate that is achieved in each environment is intrinsically related to the neutron energy spectrum at the position of irradiation. A typical fusion first wall neutron energy spectrum has a very pronounced peak at $14 \mathrm{MeV}$, which is above many reaction $\mathrm{Q}$-values. This makes the fusion environment fundamentally different from the fission environment, in terms of material performance. One of the key issues to mimic fusion conditions is to have similar gas production (mainly Helium) to dpa ratio. Helium and Hydrogen are the most likely gases to be produced during neutron irradiation. Helium can be found as
Table 2. Number of neutrons grossing an area of $2 \mathrm{~cm} 2$,perpendicular to
the beam direction, placed at different distances from the baek-plate.

\begin{tabular}{|c|c|c|c|c|c|}
\hline $\begin{array}{l}\text { Dist. } \\
\text { (cm) }\end{array}$ & Total & $\begin{array}{l}\text { Neutron } \\
20<E<25\end{array}$ & $\begin{array}{l}\text { Current } \\
25<E<30\end{array}$ & $\begin{array}{l}\text { (n } / \text { sec) } \\
30<E<40\end{array}$ & $40<\mathrm{E}<50$ \\
\hline $\begin{array}{l}0.0 \\
5.0 \\
10.0\end{array}$ & $\begin{array}{l}8.80 \mathrm{e}+14 \\
3.43 \mathrm{e}+14 \\
1.68 \mathrm{e}+14\end{array}$ & $\begin{array}{l}1.76 e+13 \\
8.77 e+12 \\
3.85 e+12\end{array}$ & $\begin{array}{l}6.70 \mathrm{e}+12 \\
2.72 \mathrm{e}+12 \\
1.35 \mathrm{e}+12\end{array}$ & $\begin{array}{l}5.85 e+12 \\
2.95 e+12 \\
1.39 e+12\end{array}$ & $\begin{array}{l}1.29 \mathrm{e}+11 \\
1.28 \mathrm{e}+11 \\
1.02 \mathrm{e}+11\end{array}$ \\
\hline
\end{tabular}

Deuteron Energy $=35 \mathrm{MeV}$
\begin{tabular}{l|l|l|l|l|l|}
0.0 & $1.13 \mathrm{e}+15$ & $3.63 \mathrm{e}+13$ & $1.40 \mathrm{e}+13$ & $1.01 \mathrm{e}+13$ & $2.44 \mathrm{e}+12$ \\
5.0 & $4.56 \mathrm{e}+14$ & $1.92 \mathrm{e}+13$ & $6.74 \mathrm{e}+12$ & $4.08 \mathrm{e}+12$ & $1.32 \mathrm{e}+12$ \\
10.0 & $2.30 \mathrm{e}+14$ & $9.26 \mathrm{e}+12$ & $3.32 \mathrm{e}+12$ & $1.98 \mathrm{e}+12$ & $8.40 \mathrm{e}+11$ \\
\hline
\end{tabular}

Deuteron Energy $=40 \mathrm{MeV}$
\begin{tabular}{l|l|l|l|l|l|}
0.0 & $1.37 \mathrm{e}+15$ & $6.40 \mathrm{e}+13$ & $2.61 \mathrm{e}+13$ & $1.67 \mathrm{e}+13$ & $4.11 \mathrm{e}+12$ \\
5.0 & $5.75 \mathrm{e}+14$ & $3.34 \mathrm{e}+13$ & $1.33 \mathrm{e}+13$ & $7.39 \mathrm{e}+12$ & $1.99 \mathrm{e}+12$ \\
10.0 & $2.98 \mathrm{e}+14$ & $1.70 \mathrm{e}+13$ & $6.83 \mathrm{e}+12$ & $3.53 \mathrm{e}+12$ & $1.19 \mathrm{e}+12$ \\
\hline
\end{tabular}

${ }^{3} \mathrm{He}$ or ${ }^{4} \mathrm{He}$ (alpha) and Hydrogen as ${ }^{1} \mathrm{H}$ (protium), ${ }^{2} \mathrm{H}$ (deuterium), or ${ }^{3} \mathrm{H}$ (tritium). The reactions that produce these

isotopes include all reactions that have these isotopes in the exit channel.

In this section, the gas generation for three different deuteron beam energies is presented, and these values are compared with gas production calculated for a typical fusion reactor. The elements selected to perform the comparisons were Iron, Vanadium, and Chromium, the deuteron energies were 30,35 , and $40 \mathrm{MeV}$, and finally the fusion reactor designs considered were the ITER and the European DEMO. The values for both, ITER and DEMO, were calculated using the MCNP code and are normalized for a neutron wall loading of $2 \mathrm{MW} / \mathrm{m}^{2}$ and a full power year of operation [3]. The calculated values for the three deuteron energies of IFMIF are presented for different locations inside the test assembly region in the direction of the beam center line. The neutron transport for IFMIF was performed using MCNP code. The magnitude and spectrum of the calculated neutron flux were used by a post-processor code to calculate the dpa rate and gas production. The damage cross sections used are from reference [4] and gas production from reference [5].

Table 3 summarizes the calculated results for all cases analyzed. It can be noticed that by increasing the deuteron energy, the general trend for these materials, concerning $\mathrm{He}$ to dpa ratio, is to approach the fusion responses. The responses from IFMIF are not exactly the same as the calculated responses for a fusion first-wall environment; however, the most important response, helium to dpa ratio, is very close to the fusion responses. Also, the hydrogen production is similar to the fusion cases. 
Table 4 presents, for Iron and Vanadium, the values of displacement rate, helium and hydrogen production, and gas production to dpa ratios for a $40 \mathrm{MeV}$ deuteron beam for Table 3. Gas production to dpa rates for three deuteron beam energies ctiviared with fusion reactor values. The distance indicated into the table $(d=x . c m)$ refers to the distance from the point where the flux was calculated to the back-plate.

Helium to DPA ratio

\begin{tabular}{|c|c|c|c|}
\hline & Iron & Vanadium & Chromium \\
\hline $30 \mathrm{MeV}-\mathrm{d}=0 . \mathrm{cm}$ & 6.87 & 3.30 & 6.05 \\
$30 \mathrm{MeV}-\mathrm{d}=5 . \mathrm{cm}$ & 7.92 & 4.29 & 7.79 \\
$35 \mathrm{MeV}-\mathrm{d}=0 . \mathrm{cm}$ & 8.02 & 4.52 & 8.03 \\
$35 \mathrm{MeV}-\mathrm{d}=5 . \mathrm{cm}$ & 9.12 & 5.70 & 10.12 \\
$40 \mathrm{MeV}-\mathrm{d}=0 . \mathrm{cm}$ & 9.09 & 5.82 & 10.12 \\
$40 \mathrm{MeV}-\mathrm{d}=5 . \mathrm{cm}$ & 10.16 & 7.16 & 12.44 \\
ITER-inboard & 11.26 & 5.50 & 17.86 \\
DEMO-outboard & 10.40 & 4.85 & 16.11 \\
\hline
\end{tabular}

Hydrogen to DPA ratio

\begin{tabular}{|c|c|c|c|}
\hline & Iron & Vanadium & Chromium \\
\hline $30 \mathrm{MeV}-0 . \mathrm{cm}$ & 39.6 & 14.2 & 35.4 \\
$30 \mathrm{MeV}-5 . \mathrm{cm}$ & 44.9 & 17.4 & 44.4 \\
$35 \mathrm{MeV}-0 . \mathrm{cm}$ & 45.7 & 17.9 & 46.3 \\
$35 \mathrm{MeV}-5 . \mathrm{cm}$ & 51.9 & 21.5 & 57.2 \\
$40 \mathrm{MeV}-0 . \mathrm{cm}$ & 52.0 & 21.7 & 58.0 \\
$40 \mathrm{MeV}-5 . \mathrm{cm}$ & 58.4 & 25.5 & 70.3 \\
ITER - inboard & 44.1 & 23.0 & 44.8 \\
DEMO-outboard & 41.0 & 20.4 & 41.3 \\
\hline
\end{tabular}

several positions inside the test assembly region. Iron and Vanadium where chosen in this analysis because of the likelihood of these elements being the most important components of advanced alloys for fusion applications.

The numbers presented in Table 4 indicate that IFMIF operating with $40 \mathrm{MeV}$ deuterons will produce suitable damage and gas production for fusion materials development. The amount of hydrogen produced in Iron and the helium produced in vanadium is expected to be larger than the one predicted for the fusion environment, otherwise the numbers are very compatible between IFMIF and fusion reactors. Then, one can conclude that, in going to a higher deuteron energy, for these elements, there is no unacceptable increase in gas production and in the corresponding transmutation products (the transmutation products are restricted in number to the same 'appm' levels as the gas production and so are in agreement with the predictions for a fusion environment).

The only reactions not included in this analysis are the neutron-neutron reactions (this is $\left(n, n^{\prime}\right),(n, 2 n),(n, 3 n)$, etc) and the neutron capture (neutron-gamma). The neutron capture reaction is expected to have an insignificant effect in the neutron energy range of concern. On the other hand, the neutron-neutron reactions can have some effect if the resulting isotope decays with relatively short half-life; however, this is not expected to have a major effect on the material properties.

\section{Influence of the Deuteron Energy on the Testing Volume}

The testing volume with dpa rate above a threshold value is an important parameter to define the distribution of samples in the test assembly region and to qualify the performance of the machine in terms of fusion materials development. A volume of $500 \mathrm{~cm}^{3}$ with dpa rate above $20 \mathrm{dpa} / \mathrm{fpy}$ is considered necessary for fusion materials development [6].

Table 4. Nuclear Responses for a $40 \mathrm{MeV}$ deuteron beam at several distances from the back-plate, for the inboard first-wall of ITER and for the outboard first-wall of the European DEMO. The responses are for one full power year of operation. ITER and DEMO have their responses normalized to $2 \mathrm{MW} / \mathrm{m}^{2}$

Iron - $40 \mathrm{MeV}$ deuterons

\begin{tabular}{|c|c|c|c|c|c|}
\hline & $\begin{array}{c}\text { Damage } \\
\text { (dpa) }\end{array}$ & $\begin{array}{c}\mathrm{He} \\
\text { (appm) }\end{array}$ & $\begin{array}{c}\mathrm{H} \\
\text { (appm) }\end{array}$ & $\begin{array}{l}\text { He/dpa } \\
\text { ratio }\end{array}$ & $\begin{array}{l}\text { H/dpa } \\
\text { ratio }\end{array}$ \\
\hline 0 . & 58.1 & 528. & 3020. & 9.09 & 52.0 \\
\hline 2.50 & 33.3 & 330. & 1890. & 9.91 & 56.7 \\
\hline 5.50 & 18.9 & 192. & 1100. & 10.2 & 58.4 \\
\hline 11.00 & 8.9 & 89.0 & 510. & 10.0 & 57.4 \\
\hline 17.50 & 4.3 & 41.1 & 240. & 9.56 & 55.3 \\
\hline \multicolumn{6}{|c|}{ Iron - ITER \& Euro DEMO } \\
\hline $\begin{array}{l}\text { Reactor } \\
\text { Design }\end{array}$ & $\begin{array}{c}\text { Damage } \\
\text { (dpa) }\end{array}$ & $\begin{array}{c}\mathrm{He} \\
\text { (appm } \\
\end{array}$ & $\begin{array}{c}\mathrm{H} \\
\text { (appm }\end{array}$ & $\begin{array}{l}\overline{\mathrm{He} / \mathrm{dpa}} \\
\text { ratio }\end{array}$ & $\begin{array}{l}\text { H/dpa } \\
\text { ratio }\end{array}$ \\
\hline $\begin{array}{l}\text { ITER inb } \\
\text { mid-plane }\end{array}$ & 20.2 & 227 & 890. & 11.3 & 44.1 \\
\hline $\begin{array}{l}\text { DEMO } \\
\text { outb mid- } \\
\text { plane }\end{array}$ & 17.3 & 180. & 708. & 10.4 & 40.9 \\
\hline
\end{tabular}

Vanadium - $40 \mathrm{MeV}$ deuterons

\begin{tabular}{|c|c|c|c|c|c|}
\hline & $\begin{array}{c}\text { Damage } \\
\text { (dpa) }\end{array}$ & $\begin{array}{c}\mathrm{He} \\
\text { (appm) }\end{array}$ & $\begin{array}{c}\mathrm{H} \\
\text { (appm) }\end{array}$ & $\begin{array}{c}\text { He/dpa } \\
\text { ratio }\end{array}$ & $\begin{array}{c}\text { H/dpa } \\
\text { ratio }\end{array}$ \\
\hline 0. & 60.2 & 350. & 1305. & 5.82 & 21.7 \\
2.50 & 34.6 & 235. & 850. & 6.79 & 24.6 \\
5.50 & 19.7 & 141. & 500. & 7.16 & 25.5 \\
11.0 & 9.4 & 67.2 & 240. & 7.14 & 25.2 \\
17.50 & 4.6 & 31.8 & 110. & 6.87 & 24.1 \\
\hline
\end{tabular}

Vanadium - ITER \& Euro DEMO

\begin{tabular}{|c|c|c|c|c|c|}
\hline $\begin{array}{c}\text { Reactor } \\
\text { Design }\end{array}$ & $\begin{array}{c}\text { Damage } \\
\text { (dpa) }\end{array}$ & $\begin{array}{c}\mathrm{He} \\
\text { (appm }\end{array}$ & $\begin{array}{c}\mathrm{H} \\
\text { (appm }\end{array}$ & $\begin{array}{c}\text { He/dp } \\
\text { a ratio }\end{array}$ & $\begin{array}{c}\text { H/dpa } \\
\text { ratio }\end{array}$ \\
\hline $\begin{array}{c}\text { ITER inb } \\
\text { mid-plane } \\
\text { DEMOO outb } \\
\text { mid-plane }\end{array}$ & 20.7 & 114. & 477. & 5.50 & 23.0 \\
\hline
\end{tabular}

A major advantage of increasing the deuteron energy in IFMIF is the accomplishment of an increase in testing volume. As mentioned above, the available testing volume is increased without requiring the incorporation of another beam accelerator line to the design (the maximum current that a deuteron beam accelerator line can deliver is around $125 \mathrm{~mA}$ ). Table 5 presents the available volume above dpa threshold values for 30,35 , and $40 \mathrm{MeV}$ deuteron beams. The material loading inside the test assembly region is $50 \%$ Iron and $50 \%$ vacuum. These results indicate that there is a considerable gain in terms 
of volume by increasing the deuteron energy. As one can see, $40 \mathrm{MeV}$ deuterons produce a volume with dpa above 20 $\mathrm{dpa} / \mathrm{fpy}$ that is equivalent to the volume with dpa above 15 dpa/fpy produced by a $35 \mathrm{MeV}$ deuteron beam. This shows ii... a $40 \mathrm{MeV}$ deuteron beam with $250 \mathrm{~mA}$ of current is roughly equivalent to a $35 \mathrm{MeV}$ deuteron beam with $330 \mathrm{~mA}$. If one considers a $30 \mathrm{MeV}$ deuteron beam, the difference is much larger and the equivalence in this case is almost 2 to 1 in terms of current required to achieve the same volume above a given dpa rate level. There is a definite advantage, in terms of testing volume, by increasing the deuteron energy to 40 $\mathrm{MeV}$ in the IFMIF design.

Table 5. Volume with dpa rate above the listed threshold value for a 30,35 , and $40 \mathrm{MeV}$ deuteron beam with $250 \mathrm{~mA}$ of current. The beam footprint on the lithium jet is $5 \times 20 \mathrm{~cm}^{2}$.

\begin{tabular}{|c|c|c|c|}
\hline $\begin{array}{c}\text { DPA } \\
\text { threshold } \\
\text { (dpa/fpy) }\end{array}$ & $\begin{array}{c}\text { Deuteron } \\
\text { Energy } \\
40 \mathrm{MeV}\end{array}$ & $\begin{array}{c}\text { Deuteron } \\
\text { Energy } \\
35 \mathrm{MeV}\end{array}$ & $\begin{array}{c}\text { Deuteron } \\
\text { Energy 30 } \\
\text { MeV }\end{array}$ \\
\hline 10 & 1405. & 949. & 588. \\
15 & 754. & 498. & 284. \\
20 & 471. & 292. & 145. \\
25 & 304. & 169. & 62. \\
30 & 196. & 96. & 16. \\
40 & 72. & 13. & 0. \\
50 & 8.5 & 0. & 0. \\
\hline
\end{tabular}

4. Influence on the atomic displacement rate gradient.

The gradient of the neutron flux/ nuclear responses is required to be kept around $10 \% / \mathrm{cm}$ inside the test assembly region. It is arguable that an increase in the deuteron energy can produce unacceptable increase in the flux gradient. In this section, results are presented regarding the influence of the deuteron energy on the atomic displacement rate gradient. Figure 1 displays a comparison of the dpa rate gradient for three deuteron energies $(30,35$, and $40 \mathrm{MeV})$. The beam current is $250 \mathrm{~mA}$ and the beam footprint is $5 \times 20 \mathrm{~cm}^{2}$ for all cases. As one can see, the gradient for a $40 \mathrm{MeV}$ deuteron beam is actually lower than the gradient for both, 35 and $30 \mathrm{MeV}$ deuteron beams. In terms of the dpa rate gradient, the higher deuteron energies provide an advantage through a reduction in the gradient.

\section{Conclusions}

This study has demonstrated that there is no measurable penalties, for the elements analyzed, in increasing the deuteron energy from $30,35 \mathrm{MeV}$ to $40 \mathrm{MeV}$ for IFMIF. It was shown that the gas production for the elements analyzed is close to the calculated values for a fusion reactor. Also, in terms of gradient of the nuclear responses, the performance of the higher deuteron energy beam has shown to be better than the lower ones, meaning that a beam with higher deuteron energy produces a more spatially uniform atomic displacement rate than the lower deuteron energy beams.

In terms of the testing volume the gains obtained by increasing the deuteron energy to $40 \mathrm{MeV}$ are also quite significant, and important savings in accelerator costs can be achieved by increasing the deuteron energy. This study has shown substantial advantages for the option of having IFMIF designed for a $40 \mathrm{MeV}$ deuteron beam.

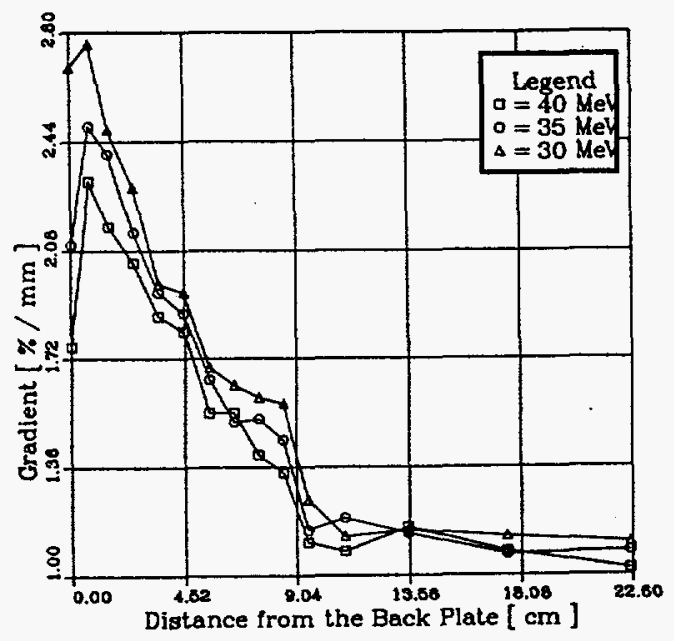

Figure 1. Atomic displacement rate gradient for three deuteron energies as a function of the position relative to the back-plate in the direction of the beam center line. The beam current is $250 \mathrm{~mA}$ and the beam footprint on the jet is $5 \times 20 \mathrm{~cm}^{2}$.

\section{References}

1. Gomes, I.C., "Analysis of the Neutron Generation from a D-Li Neutron Source," Argonne National Laboratory Report ANL/FPP/TM-265, 1994.

\section{Briesmeister, J., Editor, "MCNP - A General Monte Carlo Code for Neutron and Photon Transport," LA-7396-M, 1986}

3. Fischer, U., "Detailed Neutronics Analysis for a Test Cell with Standard Loading Configuration," Proceedings of the IEA-Technical Workshop on the Test Cell System for a International Fusion Materials Irradiation Facility, Karlsruhe, Germany, July 3-6, 1995.

\section{Greenwood, L.R., personal communication.}

5. Mann, F., "REAC-3 - A Computer Code System for Activation and Transmutation," Hanford Engineering Development Laboratory Report HEDL-TME-81-37, 1993.

\section{Zinkle, S., personal communication.}

Work supported by the US Department of Energy, Office of Fusion Energy, under Contract No. W-31-109-Eng-38 